\title{
Records of Engagement and Decision Tracking for Adaptive Management and Policy Development
}

\author{
Pierre Glynn and Carl D. Shapiro \\ U.S. Geological Survey \\ Reston, Virginia, USA \\ Email: pglynn@usgs.gov, cshapiro@usgs.gov
}

\author{
Alexey Voinov \\ University of Technology Sydney, \\ Sydney, Australia \\ Email: aavoinov@gmail.com
}

\begin{abstract}
The management of coupled human-natural (CHN) systems, including natural resource and environmental systems, would benefit from recognition of the need to integrate, and bring critical thinking, transparency, and accountability to science and policy development. It would benefit also from: (1) stakeholder engagement and participatory processes, (2) societal and institutional continuity in science and decisions evaluation and follow-through, and (3) recognition and understanding of the role of biases, beliefs, heuristics, and values (BBHV) in decisionmaking.

We suggest that creating multi-media, efficiently accessible, "Records of Engagement" (RoE) could support meeting the above needs. RoE would offer: (1) a reward system to support and foster stakeholder engagement; (2) a record structure for evaluating processes and outcomes and for learning and knowledge transfer, and (3) an opportunity to systematize, facilitate, create efficiencies, and improve the engagement of experts and stakeholders in participatory modeling, planning and policy development. RoE, in our view, should also not only describe scientific evidence and lines of argumentation but also BBHV and emotions expressed, a first step in understanding their impacts on decision making and management of $\mathrm{CHN}$ systems.

We seek to engage readers to help us determine how to create RoE, including what they might contain to be most useful. Preliminary thoughts are offered on RoE framework design and content, and on a Decision Tracking System and methodologies that could be used to support creation and use of RoE. Some existing stakeholder engagement records are discussed in reference to the ideal $\mathrm{RoE}$ that we envision.
\end{abstract}

Keywords - Human biases; heuristics; decision tracking; open science; open policy; informatics

\section{INTRODUCTION}

Scientists, other professionals, community leaders, the interested public, and other stakeholders often come together to help manage natural resources, environmental conditions, and built infrastructure. These engagements can range from cursory exchanges of information and opinions to more indepth participatory processes [1] that may include participatory science (Citizen Science, but also participatory modeling), as well as participatory planning and governance. Participation typologies have also been developed that considered not only depth of public engagement, but also the degree of disagreement (amongst different experts and different constituencies) relating to either issues of science or issues of social norms and values [2]. Participatory processes are particularly valuable when there is significant disagreement in social norms and values, but can be also highly resource-intensive, especially when coupled with high degrees of science uncertainty. Indeed, these processes place great demands on organizers and stakeholders even when social norms and values are broadly shared, for example when different constituencies compete for limited goods.

We suggest that participatory processes would benefit by having more meaningful "Records of Engagement" (RoE) than currently exist for science and policy issues that cannot be well addressed with the "demarcation model" of science and policy. By Record(s) of Engagement we mean a description of the participatory processes, stakeholder perspectives offered, lines of argumentation, group dynamics, emotions expressed, and all other "engagement" aspects that together combine into decisions made to manage coupled human-natural $(\mathrm{CHN})$ systems (also sometimes referred to as socio-ecological systems).

[Note: the "demarcation model" separates science and policy through institutional or imagined walls. By reducing political interference, the separation facilitates preservation of science integrity. The model views science as providing an independent accumulation of truths and tools (which can easily be "cherry-picked" to support specific policy or management decisions). The demarcation model does not coordinate critical thinking or the structured development of integrated science and policy, such as might occur through adaptive management and structured decision-making. Consequently, the model has often been criticized [3]]. 
We recently provided a typology of $\mathrm{CHN}$ science and policy issues, and we argued for the need to have Open Traceable Accountable Policy (OTAP) integrate with Open Science [4]. [Note: the word "policy" in this paper relates to decisions or sets of decisions made consciously by policymakers and managers; we may sometimes refer to the OTAP concept as the "Open Policy" concept. It differs generally from "policy" precisely by being traceable and accountable]. We also suggested an adaptive science-infused governance cycle that explicitly seeks to recognize the role of biases, beliefs, heuristics, and values (BBHV) in both science and policy/management decisions. However, a basic element of adaptive management and adaptive governance is that followthrough is required to assess and evaluate the results of decisions made through monitoring of the systems/issues considered and through adaptive responses. Failure often occurs because of the lack of management continuity; in our view usually because the needed timescales for evaluation and adaptation are typically longer than the timescales relevant to the human actors involved in management and policy setting.

$\mathrm{CHN}$ systems and their associated management issues are complex and fraught with uncertainties and disagreements relating to the available scientific, societal, and individual knowledge, and to the associated BBHV affecting such knowledge. The paucity of meaningful RoE relating to $\mathrm{CHN}$ system issues is a key barrier to enabling informed adaptive policy responses and management decisions.

In addition to helping with the issue of continuity of $\mathrm{CHN}$ system management, RoE could help create a reward system that could help foster the engagement and recognition of participants, in some of the same ways that publications are part of a reward system for scientists and academia.

What would an ideal RoE look like, and how could it most effectively be created? In section II of this paper, we suggest that the ideas of our readers and of the IEEE Society on Social Implications of Technology (SSIT) may help answer these questions. We offer some additional questions and initial statements on what an ideal RoE might comprise that may be helpful in provoking thoughts and reactions. [Note: for purposes of this paper, we are not considering the costs of creating RoE. Although costs are real, at this stage we are examining "ideal” RoE independent of costs.]

In section III, we offer further information on our own current ideas of what RoE should contain and some thoughts as to what technologies or human processes might be used to help create them. We are similarly interested in the reactions of our readers and of the SSIT to our suggestions.

In a final section, we briefly discuss examples of records that are available for engagements involving experts and the public and mention some of the positive aspects of these records as well as some of gaps or possible improvements. We reference a case study related to the management of landuse change and nutrient inputs in the Lake Taupo watershed in New Zealand. We previously described the case study in one of our publications [4].

\section{PROVOKING QUESTIONS AND CONTEXT}

\section{A. What Would an Ideal RoE look like?}

RoE could potentially document, trace, and account for many different aspects of expert and public participatory engagements. Here, we seek to describe what could potentially be comprised in RoE to prompt thinking about what should or should not be documented.

(1) The RoE should detail the context for a specific issue or system of concern being addressed or considered by the participatory effort.

(2) The RoE should document some of the participatory activities, discussions, and intermediate results for the engagement along with the broader definition and spatiotemporal and participatory boundaries of the engagement in question.

(3) The RoE should record all the information (facts) that have been considered in the decision-making process.

(4) The RoE should list all the tools and methods used in the process and explain why and how they were selected.

(5) The RoE should document the final results of the specific engagement, the recommendations provided to decision makers, or the decisions arrived at, along with some traceability as to how those recommendations or decisions were arrived at. In cases where no recommendations or decisions were arrived at, or in cases of majority and minority opinions, some explanations of the different positions or opinions of different constituencies and some of the reasons for the lack of agreement or consensus should be given.

(6) The RoE should also have sufficient flexibility to allow inclusion of any additional information that would be considered valuable documentation for a particular issue.

The issues and systems considered by the participants in their engagement fall in the realm of coupled human-natural (CHN) systems, and the participants are likely to be part of the systems that they are trying to evaluate and help manage: they are not independent observers. What does this mean in terms of documenting RoE?

One suggestion is that it is important to document not only (1) the biophysical aspects of the CHN system, but also (2) the human and societal aspects. Another might be that because there are no independent observers, it is important to try to document (3) the perspectives and behaviors of the participants involved. Furthermore, the documentation should try to describe not only the system/issue(s) at hand, but also (4) the boundaries and boundary judgements for the system/issue(s).

The 12 questions used by Critical Systems Heuristics (CSH) theory [5], [6] offer one way to describe the boundary judgements of participants. $\mathrm{CSH}$ can help elicit thinking regarding four different categories of sources of influence (sources of motivation, control, knowledge, and legitimacy) spread across three system/issue categories (social roles, 
stakes or specific concerns, stakeholding issues or key problems). The questions solicit "boundary judgments" to inform a system (S) of interest. They examine social roles and stakeholders by asking who ought to be or is (1) an intended beneficiary, (2) in control of conditions of success, (3) providing relevant knowledge/skills, (4) representing the interests of those negatively affected but not involved. These questions in turn help phrase additional questions that help define the "stakes" or specific concerns of stakeholders. For example, what ought to be or is (1) the purpose of $S$, (2) the conditions of success, (3) relevant new knowledge or skills, (4) opportunities for the interests of those negatively affected. They then delve into stakeholding issues, asking what ought to be or is (1) S's measure of success, (2) outside the control of the decision maker, (3) regarded as assurances of successful implementation, (4) available for reconciling differing worldviews among those involved and affected.

There are many other ways of eliciting systems thinking beyond CSH. For example, Systems Intelligence [7]-[9] offers positive ways to think about CHN systems with the stated aim of making use of remarkable human capabilities (i.e. systems intelligence) to improve systems thinking. Systems Intelligence considers 8 different dimensions of human nature that can enhance systems thinking: (1) systems perception, (2) attunement (emotional, cognitive, physical, to ourselves, to others, to systems), (3) reflection, (4) positive engagement, (5) spirited discovery, (6) effective responsiveness, (7) wise action, and (8) positive attitude. There are many other types of approaches to improving evaluation and management of CHN systems, often based on the pioneering "systems thinking" and operations research studies of Russell Ackhoff and C. West Churchman (e.g. [10][12]).

One gap that we notice in many approaches is that there is a general reluctance to try to recognize, assess, and possibly counter, the role of human and community BBHV in participatory processes and in systems thinking; including amongst scientists and other "experts" who frequently consider their judgements and decisions "objective" and often lack the needed humility of the Socratic Paradox "I know that I know nothing" [13], [14]. In part, this reluctance may be due to the importance of BBHV in identifying the role of BBHV in decision making. Explicitly considering BBHV will in part require the influence of $\mathrm{BBHV}$ in its assessment. As we previously noted [4], [15], [16], this lack of consideration of BBHV in science, in policy development, and in participatory processes would not be as much of a problem if humans and their communities were well adapted to facing all the new issues of today, specifically all those related to the reality of an unprecedented human population (and associated consumption levels), an unprecedented level of science and technology, and an unprecedented global connectivity and movement of humans, biota, ideas, and materials. There are many approaches that could be used to elicit and possibly counter BBHV (when needed), including those increasingly considered by experts trying to counter "implicit bias", a narrow subset of BBHV.

\section{B. How Could Ideal RoE Be Created?}

Clearly, RoE that comprehensively describe all the elements presented above are difficult to create. The greatest difficulties are social rather than technical, although technical challenges also abound. This is especially true if RoE were designed to be as useful and accessible as possible. Given all the possible conflicting interests, there are many reasons why individuals or the constituencies that they represent would be unwilling or reluctant to have transparency on their negotiating positions. Additionally, transparency is often prized in science, but it is difficult to ask people to be transparent about their beliefs, their emotions, or more generally to be willing to reveal their BBHV. And there are many good reasons (in addition to costs) not to have transparency that could violate rights of privacy, proprietary information, community or individual security, or that could be deleterious to the "sacred values" of individuals or constituencies. Even in science, where transparency is highly prized, how often are scientists and their publishers willing to publish negative results (or other results that could harm their reputation or ability to make a living)? How would you address these issues?

Assume that you could adequately address the human and social challenges in the creation of RoE, how would you technically construct RoE so as to provide the most useful and accessible documentation?

\section{FURTHER THOUGHTS AND OUR OWN VIEWS}

Human societies are in a new era of communications and information never previously experienced. We have evolved from prehistoric times with limited abilities of communication to the age of enlightenment with the mass dissemination of knowledge and information. And we are now in an entirely new internet-fueled age of global communication, in which visuals and videos are replacing or encroaching on linear text and lines of argumentation, and where impacts and responses are highly socialized rather than dyadic. Anthropologists like Walter Ong have documented how our modes of communication have co-evolved with and affected our modes of thinking and vice-versa [17]. What does this mean for our modes of thinking in this new internet-communication age? Why does this matter for the RoE that we envisage? Our answer is simple. For RoE to be useful, they need to take advantage of all forms of communication and information documentation, but they especially need to be accessible and useful to present and future communities. This means that RoE should not just consist of linear lines of thoughts and documentation. They should be hierarchical in nature, allowing quick understanding of the main issue(s) covered by the RoE but also rapid exploration into more details on any of its aspects. Advances in search and analysis technologies, however, may mitigate the need for hierarchical organization of RoE. 
RoE should also address the circular nature of all adaptive decision making [4], which generally requires several cycles of iteration, re-evaluation, and reconsideration of decisions. It would be important for RoE to capture these iterations, and not just the final round of decision-making.

RoE should also resonate with different types of thinkers (visual thinkers, auditory thinkers, verbal thinkers, kinesthetic thinkers) and different types of intelligences [18]. This creates an additional burden on RoE documentation. Essentially meeting these needs would mean that RoE would make optimal use of different media (e.g. visual, auditory, written), and would consist of both memes (short descriptions or visualizations or other representations of ideas) and longer more linear lines of argumentation.

\section{A. Further Considerations on RoE Content and Expression}

RoE should provide the different elements described earlier, including: (1) context and history of the issue, (2) participant activities, behaviors, and discussions, and (3) summary of final results, recommendations, and decisions. Importantly, RoE should not be limited to describing scientific evidence, data, and logical lines of reasoning. It should also provide expressions, modulated as necessary to maintain effective participatory processes, of some of the emotions and innate reactions of participants (which can be anonymized or aggregated if necessary). Why do we suggest this? Fundamentally, because we believe like Hume [19] that "Reason is, and ought only to be the slave of the passions, and can never pretend to any other office than to serve and obey them." And the only way to start distinguishing reason from the passions is to let some of the passions express themselves. In more modern terms, how can we start recognizing the BBHV of people and constituencies [4] engaged in participatory processes if we don't let them express themselves? Furthermore, we believe that people will never start listening to logic, evidence and scientific reasoning if they don't share some emotional connection or other shared understanding with the people presenting the reasoning in question.

RoE should outline the nature of the system/issue, available evidence, the facilitation processes used for engagement, as well as proposed actions and governance possibilities to spur follow-through. The constituencies involved in the science and decision- making processes, and their relative power to provide knowledge and affect decisions, should also be documented. Recognizing the importance of BBHV, RoE could also detail the ethical principles, beliefs, and other factors used in arguments for suggested decisions, emotions expressed by different constituencies, and the behavioral and group dynamics of the engagement. Governance of the engagements and RoE creation processes would be critical and would emphasize achievement of stated goals, efficient collaborations, transparency, and integrity of all participants, including the information brought forward in decision-making. While ensuring that key principles of stakeholder engagement are applied and adapted as needed, we see the potential to apply information technology to support and guide the RoE processes that we envision.

\section{B. How could RoE be created?}

From a technical perspective, creating RoE is not that difficult. We propose a Decision Tracking System (DTS) that can solicit and guide input through a system of questions (e.g. such as those used in the $\mathrm{CSH}$ methodology) to be answered by the participants and policy makers involved in the process. Generating the RoE in a standardized digital format would help accessibility, analysis, and use by a diversity of technologies (e.g. artificial intelligence and natural language processing, machine vision and behavioral analysis, expert system design, gamification) and approaches (e.g. soft systems methodology, behavioral operations research). This would allow further processing, analyzing, searching, archiving and reuse of RoE. The DTS (and the RoE) would allow, with appropriate reflection/input from different constituents, some opportunity to evaluate and revisit past RoE creation decisions.

Deciding what should be in RoE - including how to manage the documentation (or not) of sensitive issues, personal emotions, beliefs, and values or how to prevent violations of privacy or proprietary information, and outlining the expectations for the RoE and policy decision follow-ups could be handled through multiple levels of access, flexible design of the process and non-obligatory mode of data solicitation. In our view, RoE and DTS should seek an appropriate balance of innate, instinctive thinking (i.e. System 1) and conscious, reflective thinking (i.e. System 2). They should also explicitly consider communications at different levels (personal, within group, external) and seek an appropriate use of memes (that people innately recognize and respond to) and of more detailed and exhaustive lines of argumentation.

The DTS could store information using an xml-based schema, allowing seamless connectivity to a variety of web technologies (e.g. Semantic Web), and modeling tools.

The biggest challenge would be on the societal side. How could RoE and DTS be implemented with some flexibility while maintaining the credibility that comes from following previously agreed-upon principles? How could incentives for RoE and DTS be created and maintained; what would motivate people to use them? Especially knowing that given RoE might conflict with certain special interests, lobbying efforts, group thinking, power asymmetries, etc.

\section{A Visual Meme for our RoE Concept}

We fully agree with C.P Snow [20] that human societal knowledge, ethics, and governance have suffered from the separation of the sciences and the humanities. In addition, we believe that we cannot start recognizing the role that our emotions and our BBHV (i.e. our passions) play in our reasoning if we do not first elicit those passions and analyze them. Art, sometimes used in the context of Soft-Systems Methodology and Rich Pictures [21], is one of the many tools 
that can help provide a useful elicitation of our innate emotions and BBHV. Here, we offer a brief analysis of a painting that in our view has some of the elements of what RoE might be, from the perspective of an individual participant. The painting is a visual meme that conveys a rich set of messages. (1) The participant, like the painting, has some transformed understanding of the past (Johannes Vermeer's painting of the "Girl with a Pearl Earring"), of the context for the issue at hand and how it may have evolved over time. (2) The participant, like the painting, displays a

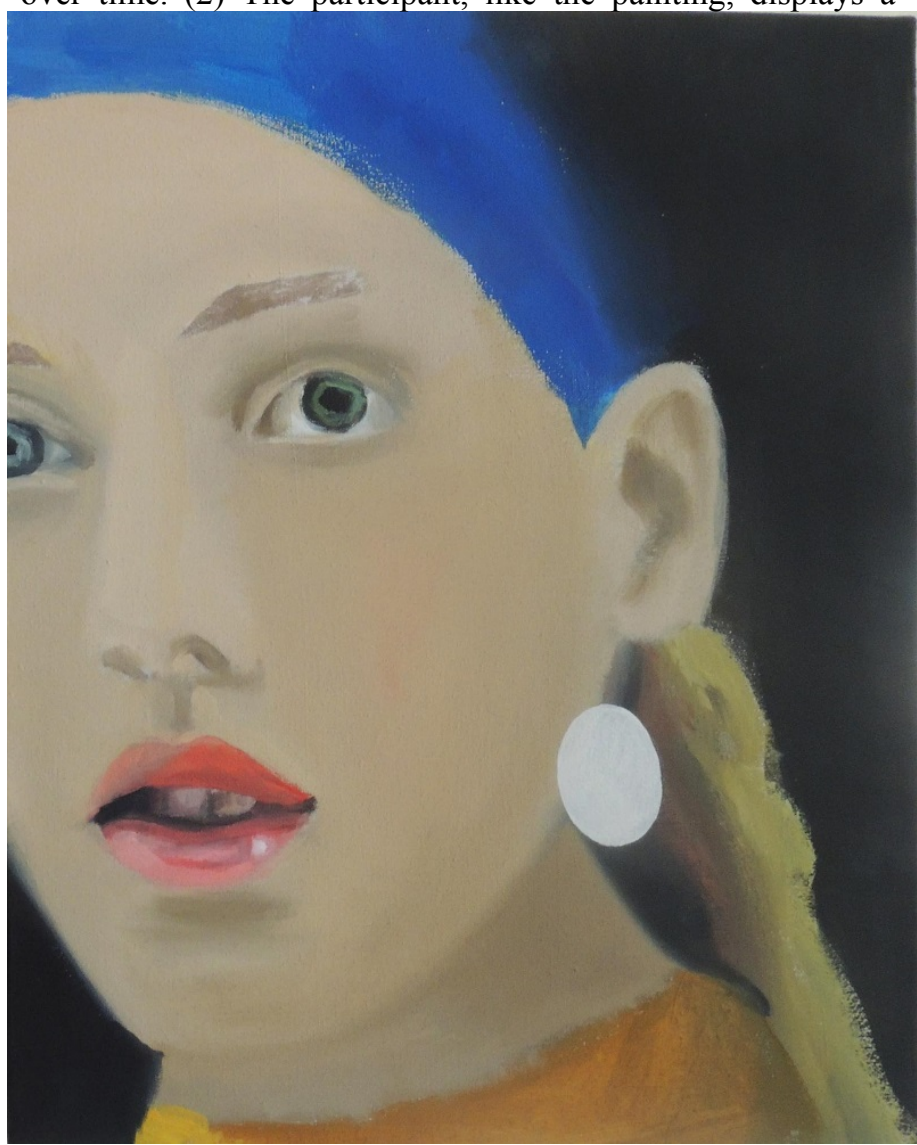

certain self-assurance in her emotions, and this includes perhaps a thirst for knowledge and for a better future. (3) The pearl in the painting is a metaphor for the goals of the participatory engagement and RoE. (4) While the painting focuses on a single participant who cannot be completely analyzed or depicted, the individual represented not only shows youthful hope in the future but also engages the viewer (and therefore other participants) in the participatory effort. (5) Lastly, the painting has a beautiful balance and structure in forms and in color, representative of what an engaging useful RoE might be.

Most importantly, this analysis clearly exemplifies the subjectivities and asymmetries involved. The viewers may or may not be aware of Vermeer's past painting. The viewers may or may not find it beautiful and balanced. They may or may not find themselves engaged and being similarly touched by what they see.

\section{ROE EXAMPLES}

We do not know of any RoE that have the richness of our ideal RoE documentation and usability. For example, the Lake Taupo (New Zealand) case study that we offered as supplementary material for our 2017 Earth's Future paper [4] had web sites ${ }^{1}$ and an excellent set of reports, some easily accessible, some less so. We were lucky to have Paul White, an expert on Lake Taupo, who had the broader view of the Lake Taupo nutrient and land-use issues as a co-author on our paper. The reports and web sites that describe the Lake Taupo issue tended to provide scientific summaries and descriptions. As any traditional scientific reports, they avoided or minimized the description of the emotions and $\mathrm{BBHV}$ of the constituencies and participants.

Taupo's Lakes and Waterways Action Group (LWAG), based around volunteers, has been the heart of the community through the development and implementation of the Lake Taupo Protection Project (LTPP) from the mid-1990s to the present day. LWAG activities have included at least 200 community meetings. Records of these activities, e.g. minutes of meetings and public comments received, are an important archive (not available on a web site) of LTPP issues, community aims, science results, and implementation concerns. Beyond the Lake Taupo situation, reporting by news media could also provide some records of stakeholder emotions and BBHV, throughout the evolution of a $\mathrm{CHN}$ system issue or situation. However, news media reports are often incomplete, sensationalized, or focused on specific advocacies or constituencies. Could they contribute to RoE nonetheless?

We have also analyzed hundreds of participatory modeling cases studies as part of a SESYNC (National SocioEnvironmental Synthesis Center) working group on participatory modeling (cf. our group's web site ${ }^{2}$ ). Typically, the records consist of minutes of meetings supplemented by the publications of scientists involved in the efforts. Failures in the participatory processes may sometimes be indirectly alluded to but are generally rarely directly reported. Emotions expressed by the constituencies are sometimes briefly mentioned, but factual descriptions of processes and findings are what is essential to getting the papers published. While our SESYNC working group has started mentioning the importance of recognizing BBHV in participatory processes [22]-[25], BBHV elicitation (and possible countering if appropriate) has not yet been put into practice. There are many examples of adaptive management or policy-setting or economic analyses where participatory processes are used to elicit the priorities and values of stakeholders or other participants. However, rarely asked or discussed is the fact that those priorities and values may reflect participant or stakeholder innate wants and BBHV's, adaptively acquired from the past - instead of what is needed by the realities of

\footnotetext{
${ }^{1}$ https://www.waikatoregion.govt.nz/council/policy-and-plans/rules-andregulation/protecting-lake-taupo/

2 www.participatorymodeling.org
} 
present or future situation(s) that may not have had any chance of getting adapted to, or carefully and logically reasoned about.

\section{CONCLUSIONS}

We hope that readers of this paper will engage with us in helping design Records of Engagement for participatory processes seeking to improve the science, policy development, and management of coupled human-natural ( $\mathrm{CHN})$ systems. We have offered some thoughts as to what RoE might comprise and how they might be created. We are not naïve about the many difficulties in creating useful accessible RoE. There are many challenges, related to human, societal, and technical issues. Several of the challenges of transparency and open access are being faced with increasing success by the Open Science movement [26]. For example, we note the new opportunities for science collaboration and transparency offered by the non-profit Center for Open Science's "Open Science Framework" ${ }^{3}$ and also the United States Government supported "Open Science Grid"4, in addition to many other science-relevant social media and science-sharing web sites. [Note: The problems faced by trying to solicit Open Traceable Accountable Policy, in our view, dwarf those faced by the Open Science movement, but on the other hand there is much to learn from the movement's experiences and progress to date. We intend to explore this opportunity in future papers.]

Despite these considerable challenges, we believe that the management of CHN systems, including those involving natural resources and environments, would benefit from transparent, accountable, and traceable practices not only in the science conducted to investigate these $\mathrm{CHN}$ systems, but also in the policy and management decisions that are made (increasingly with the inclusion of participatory processes). Creation of RoE is consequently essential, in particular to enable adaptive follow-through and the evaluations and decisions needed as a CHN system or issue evolves.

\section{ACKNOWLEDGMENT}

Any use of trade, product, or firm names in this publication is for descriptive purposes only and does not imply endorsement by the U.S. Government. The authors appreciate the efforts of Cindi Barton (USGS), Paul White (GNS Science), Kevin Breen, and three anonymous IEEE reviewers in improving this paper.

\section{REFERENCES}

[1] S. R. Arnstein, "A ladder of citizen participation," J. Am. Inst. Plan., vol. 35, pp. 216-224, 1969.

[2] M. Hurlbert and J. Gupta, "The split ladder of participation: A diagnostic, strategic, and evaluation tool to assess when participation is necessary," Environ. Sci. Policy, vol. 50, pp. 100-113, 2015.

[3] A. Liberatore and S. Funtowicz, “'Democratising' expertise, 'expertising' democracy: What does this mean, and why bother?," Sci. Public Policy, vol. 30, no. 3, pp. 146-150, Jun. 2003.

[4] P. D. Glynn, A. A. Voinov, C. D. Shapiro, and P. A. White, "From data to decisions: Processing information, biases, and beliefs for improved

\footnotetext{
${ }^{3}$ https://osf.io/

${ }^{4}$ http://opensciencegrid.org/
}

management of natural resources and environments," Earth's Futur., vol. 5 , no. $4,2017$.

[5] W. Ulrich and M. Reynolds, "Critical systems heuristics," in Systems Approaches to Managing Change: A Practical Guide, M. Reynolds and S. Holwell, Eds. London, UK: Springer-Verlag, 2010, pp. 243-292.

[6] W. Ulrich and M. Reynolds, "Systems approaches to managing change: A practical guide," in Systems Approaches to Managing Change: A Practical Guide, no. May, M. Reynolds and S. Holwell, Eds. London: Springer, 2010, pp. 243-292.

[7] R. P. Hämäläinen and E. Saarinen, "Systems intelligence - The way forward? A note on Ackoff's 'why few organizations adopt systems thinking," Syst. Res. Behav. Sci., vol. 25, no. 6, pp. 821-825, 2008.

[8] E. Saarinen and R. P. Hämäläinen, "Systems Intelligence: Connecting Engineering Thinking with Human Sensitivity," in Systems Intelligence - Discovering a Hidden Competence in Human Action and Organizational Life, no. October, R. P. Hamalainen and E. Saarinen, Eds. Helsinki: Helsinki University of Technology: Systems Analysis Laboratory Research Reports, A88, 2004, pp. 51-78.

[9] R. P. Hämäläinen, R. Jones, and E. Saarinen, "Being Better Better: Living with Systems Intelligence," Helsinki, 2014.

[10] C. W. Churchman and R. L. Ackoff, "Varieties of Unification," Philos. Sci., vol. 13, no. 4, p. 287, 1946.

[11] R. L. Ackoff, The Art of Problem Solving. New York: John Wiley \& Sons, 1987.

[12] C. W. Churchman, The Systems Approach. New York: Delta, 1968.

[13] P. D. Glynn, A. A. Voinov, C. D. Shapiro, and P. A. White, "Response to Comment by Walker et al. on 'From Data to Decisions: Processing Information, Biases, and Beliefs for Improved Management of Natural Resources and Environments," Earth's Futur., vol. 6, no. 5, pp. 762$769,2018$.

[14] W. Walker, V. Marchau, P. Bloemen, J. Lawrence, R. Lempert, and J. Kwakkel, "Comment on 'From Data to Decisions: Processing Information, Biases, and Beliefs for Improved Management of Natural Resources and Environments' by Glynn et al .," Earth's Futur., vol. 6, no. 5, pp. 757-761, 2018.

[15] P. D. Glynn, “Integrated Environmental Modelling: Human Decisions, Human Challenges," in Integrated Environmental Modelling to Solve Real World Problems: Methods, Vision and Challenges, vol. 408, no. 1, A. T. Riddick, H. Kessler, and J. R. A. Giles, Eds. Geological Society of London, 2017.

[16] P. D. Glynn, "W(h)ither the Oracle ? Cognitive Biases and Other Human Challenges of Integrated Environmental Modeling," in 7th Intl. Congress on Env. Modelling and Software, 2014, vol. 2, p. 8.

[17] W. J. Ong, Orality and Literacy: The Technologizing of the World, 2nd (2002). Routledge, 1982.

[18] H. Gardner, Frames of Mind: The Theory of Multiple Intelligences, 3rd ed. Basic Books, 2011.

[19] D. Hume, A Treatise of Human Nature. Project Gutenberg.

[20] C. P. Snow, The Two Cultures. Cambridge University Press, 1959.

[21] P. Checkland, Systems Thinking, Systems Practice. Chichester: John Wiley, 1999.

[22] A. Voinov, N. Kolagani, M. K. McCall, P. D. Glynn, F. O. Ostermann, P. Ramu, S. A. Pierce, M. E. Kragt, F. O. Ostermann, S. A. Pierce, and P. Ramu, "Modelling with stakeholders - Next generation," Environ. Model. Softw., vol. 77, pp. 196-220, 2016.

[23] S. Gray, A. Voinov, M. Paolisso, R. Jordan, T. BenDor, P. Bommel, P. Glynn, B. Hedelin, K. Hubacek, J. Introne, N. Kolagani, B. Laursen, C. Prell, L. Schmitt Olabisi, A. Singer, E. Sterling, M. Zellner, L. SchmittOlabisi, A. Singer, E. Sterling, and M. Zellner, "Purpose, processes, partnerships, and products: four Ps to advance participatory socioenvironmental modeling," Ecol. Appl., vol. 28, no. 1, pp. 46-61, Sep. 2018.

[24] R. Jordan, S. Gray, M. Zellner, P. D. Glynn, A. Voinov, B. Hedelin, E. Sterling, K. Leong, L. Schmitt-Olabisi, K. Hubacek, P. Bommel, T. BenDor, A. Jetter, B. Laursen, A. Singer, P. Giabbanelli, N. Kolagani, L. Basco Carrera, and K. Jenni, "Twelve Questions for the Participatory Modeling Community," Earth's Futur., vol. 6, 2018.

[25] E. Sterling, M. Zellner, K. Leong, K. Jenni, R. Jordan, P. D. Glynn, T. 
BenDor, A. Jetter, L. Schmitt-Olabisi, M. Paolisso, K. Hubacek, P. Bommel, and S. Gray, "Try, Try again: Lessons Learned from Success and Failure in Participatory Modeling," Elementa, vol. In press, 2018.

[26] H. Hackmann and G. Boulton, "Science for a sustainable and just world: A new framework for global science policy," in UNESCO Science
Report: Towards 2030, 2016 revis., Paris: UNESCO (United Nations Educational, Scientific and Cultural Organization), 2015, p. 818. 